\title{
PENGELOLAAN SISTEM INVENTORI PADA PT. INDOMARCO PRISTAMA MENGGUNAKAN ANALISIS ECONOMIC ORDER QUANTITY
}

\author{
Bambang Suyono ${ }^{1)}$, Wirta Agustin ${ }^{2}$, Yoyon Efendi ${ }^{3)}$ \\ 1,2,3 Teknik Informatika, STMIK Amik Riau, Jl. Purwodadi Km 10,5 Pekanbaru \\ email: bambangsyn@ @mail.com, wirtaagustin@stmik-amik-riau.ac.id, yoyonefendi@stmik-amik-riau.ac.id
}

\begin{abstract}
Inventory becomes a problem in PT. Indomarco Prismatama because it is still manual data collection and only use Microsoft Excel application. In the stock supply recapitulation takes a long time. Besides, the difficulty of the supply can be a deficiency and many more items will be stored.So required appropriate and appropriate methods in controlling the work (inventory). One preferred method is EOQ (Economic Order Quantity) which can be used in determining and evaluating effective performance. EOQ is the quantity of goods obtained with minimal cost or optimal amount as the optimal number of purchases. With the provisions of this inventory can be known the number of orders every time appropriately. Will improve the service as it delivers goods according to customer's wishes according to the Demand. It can also cause the cost of storing goods that are too expensive. To compile can make good decisions with valid and accurate information.
\end{abstract}

Keywords: Inventory System, Economic Order Quantity, PT. Indomarco Pristama.

\begin{abstract}
Abstrak
Persediaan menjadi masalah dalam PT. Indomarco Prismatama karena disebabkan pendataan masih bersifat manual dan hanya menggunakan aplikasi Microsoft Excel. Dalam rekapitulasi persedian stok membutuhkan waktu yang lama. Disamping itu sulit mengatur persedian akibatnya stok bisa mengalami kekurangan akan mengalami rugi dan kelebihan akan banyak barang yang disimpan.

Maka diperlukan metode yang baik dan tepat dalam mengontrol persediaan (inventori). Salah satu metode yang dibuthkan adalah EOQ (Economic Order Quantity) diharapkan dapat membantu dalam menentukan dan mempertimbangkan pengendalian persediaan yang efektif. EOQ adalah kuantitas barang yang diperoleh dengan biaya minimal atau sering dikatakan sebagai jumlah pembelian optimal. Dengan adanya pengelolaan sistem inventori ini dapat mengetahui jumlah pesanan setiap waktu secara tepat. Akan meningkatkan layanan karena memberikan barang sesuai dengan keinginan konsumen sesuai dengan permintaan. Selain itu juga dapat menekan biaya penyimpan barang yang terlalu banyak akibat besarnya stok. Untuk pimpinan dapat mengambil keputusan secara baik dengan informasi yang valid dan akurat.
\end{abstract}

Kata Kunci: Sistem Inventori, Economic Order Quantity, PT. Indomarco Pristama.

\section{PENDAHULUAN}

Persediaan (inventory) adalah barang atau bahan yang merupakan salah satu kekayaan organisasi yang disimpan dalam antisipasinya terhadap pemenuhan permintaan(Amrillah, Za, \& Np, 2016).

Efektivitas biaya persediaan ini dapat dilakukan dengan melakukan manajemen persediaan pada perusahaan tersebut, karena tanpa manajemen persediaan, perusahaan akan mengalami kelebihan atau kekurangan persediaan bahan baku. Ada beberapa alasan sehingga efektivitas perusahaan ini menjadi sangat penting. Alasan pertama yaitu penyimpanan bahan yang diperlukan perusahaan agar dapat memenuhi pesanan pembeli dalam waktu yang cepat(Gede Agus Darmawan, Wayan Cipta, 2015).
Pengendalian persediaan dalam perusahaan tentunya diusahakan untuk dapat menunjang kegiatan-kegiatan yang ada dalam perusahaan. Keterpaduan dari seluruh pelaksanaan kegiatan yang ada dalam perusahaan akan menunjang terciptanya pengendalian bahan bakuyang baik. Pengendalian persediaan merupakan fungsi manajerial yang sangat penting bagiperusahaan karena persediaan fisik pada perusahaanakan melibatkan investasi yang besar. Pelaksanaan fungsi akan berhubungan dengan seluruh bagian yang bertujuan agar usaha penjualan produk dan penggunaan sumber daya dapat maksimal(Saragi \& Setyorini, 2014).

Metode EOQ berusahamencapai tingkat persediaan yang seminimu mmungkin, biaya rendah dan mutu yang lebih 
baik.Perencanaan metode EOQ dalam suatu perusahaan akan mampu meminimalisasi terjadinya out ofstock sehingga tidak mengganggu proses dalam perusahaan dan mampu dalam menghemat biaya persediaaan yang dikeluarkan oleh perusahaan karena adanya efisiensi persediaan bahan baku di dalam perusahaan yang bersangkutan (Hotasadi, 2017).

PT. Indomarco Prismatama termasuk perusahaan retail terbesar di Indonesia, dengan tokonya Indomaret. Indomaret merupakan minimarket yang menyediakan kebutuhan pokok dan kebutuhan sehari-hari. Seiring dengan perjalanan waktu indomaret berkembang sangat pesat dengan toko mencapai lebih dari 11.285 , yang terdiri dari $40 \%$ toko milik terwaralaba dan $60 \%$ toko milik perusahaan, sebagian besar pasokan dari 22 pusat distribusi indomaret yang menyediakan 4800 jenis produk.

Dari semangkin banyaknya toko indomaret, semangkin sulit dalam menghitung kebutuhan barang yang ada diindomaret dan dalam penghitungan datanya masih menggunakan Microsoft excel. Data diambil dari data harian toko setiap harinya, yang didalamnya terdapat data penjualan. Data tersebut direkap secara satu persatu dan belum menggunakan aplikasi khusus. Sehingga membutuhkan waktu yang cukup lama, serta persediaan stok barang tidak terkontrol.

\section{Tinjauan Pustaka \\ Sistem Inventori}

Sistem adalah kumpulan komponen baik phisik yang saling berhubungan satu dengan yang lainnya dan berkerja sama untuk mencapai satu tujuan tertentu.

Persediaan (inventory) adalah posposaktiva yang dimiliki oleh perusahaan untukdijual dalam operasi bisnis normal, ataubarang yang akan digunakan atau dikonsumsi.Investasi dalam persediaan merupakan aktiva

lancar paling besar dari perusahaan barangdagang dan manufaktur(Syamfithriani, Muhamad, \& Putra, 2016).

Inventory merupakan istilah umum yang digunakan untuk berbagai jenis persediaan, Persediaanyang diadakan mulai dari bentuk bahan mentah, barang setengah jadi sampai dengan barang jadi, danberguna untuk:
1. Mengurangi resiko keterlambatan datangnya bahan-bahan yang dibutuhkan untuk menunjang prosesproduksi perusahaan.

2. Mengurangi resiko penerimaan bahan baku yang dipesan tetapi tidak sesuai dengan pesanansehingga harus dikembalikan.

3. Menyimpan bahan/barang yang dihasilkan secara musiman sehingga dapat digunakan seandainyapun bahan/barang itu tidak tersedia di pasaran.

4. Mempertahankan stabilitas operasi produksi perusahaan, berarti menjamin kelancaran proses produksi.

5. Upaya penggunaan mesin yang optimal, karena terhindar dari terhentinya operasi produksi karenaketidakadaan persediaan (stock out).

6. Memberikan layanan kepada langganan secara lebih baik. Barang cukup tersedia di pasaran, agarada setiap waktu diperlukan. Khusus untuk barang yang dipesan (job order), barang dapat selesaipada waktunya sesuai dengan yang dijanjikan (delivery date)(Kustanto, 2015).

Manajemen inventory adalah suatu sistem yang bertanggung jawab untuk merencanakan dan mengawasi inventory mulai tahap raw material sampai ke pelanggan. Agar suatu badan usaha memperoleh keuntungan yang optimal maka manajemen inventory harus bertujuan sebagai berikut :

1. Pelayanan pelanggan yang maksimal

2. Biaya operasional yang rendah

3. Investasi inventory yang minimal

Karena inventory disimpan digudang, maka secara fisik manajemen inventory dan gudang sangat berkaitan. Dalam situasi lain perputaran inventory sangat cepat dan gudang berfungsi sebagai pusat distribusi.

System persediaan bisadiartikan sebagai serangkaian kebijakan dan pengendalian yang memantau dan memonitor jumlah dan tingkat persediaan agar bisa menentukan tingkat persediaan yang harus dijaga, kapan persediaan harus tersedia dan berapa besar order yang harus dilakukan.Tujuan dari system ini yaitu untuk menetapkan dan menjamin tersedianya sumber daya yang 
tepat, dalam kuantitasyang tepat, dan pada waktu yang tepat(Wardhani, 2015).

\section{EOQ ( Economic Order Quantity )}

Salah satu model persediaan yang paling banyak digunakan adalah model kuantitas pesanan ekonomis (Economic Order Quantity---EOQ model). Metode EOQ berusaha mencapai tingkat perse-diaan seminimum mungkin, biaya rendah dan mutu yang lebih baik. Perencanaan persediaan yang menggunakan metode EOQ dalam suatu perusahaan akan mampu meminimalisasi terjadinya out of stock sehingga tidak mengganggu proses produksi dalam perusahaan dan mampu menghemat biaya persediaan bahan baku dalam perusahaan(Andira, 2014).

EOQ multi item merupakan model EOQ untuk pembelianbersama beberapa jenis item, dengan asumsi:

1. Tingkat permintaan untuk setiap item bersifat konstan dandiketahui dengan pasti.

2. Lead time untuk setiap itemnya sama.

3. Biaya penyimpanan, harga perunit, biaya pemesanan untuksetiap itemnya diketahui.

4. Biaya pemesanan dan penyimpanan untuk tiap itemnyasama(Suryani, 2012).

terdiri dari :

$$
\text { Economic Order Quantity ( EOQ ) }
$$

1. Biaya Pemesanan ( Ordering Cost / set up cost)

Biaya pemesanan adalah semua biaya dari persiapan pemesanan sampai barang yang dipesan datang.Sifat dari Ordering Cost adalah Konstan, tidak tergantung pada jumlah barang yang dipesan. Biaya biaya pemesanan meliputi :

a. Biaya persiapan pemesanan

b. Biaya mengirim atau menugaskan karyawan untuk melakukan pemesanan.

c. Biaya saat penerimaan barang yang dipesan

d. Biaya penyelesaian pembayaran pemesanan

2. Biaya penyimpanan di gudang ( Inventory Carrying Cost)

Biaya penyimpanan ini terdiri dari :

a. Biaya sewa gudang

b. Biaya pemeliharaan barang atau bahan

c. Biaya asuransi barang

\section{d. Biaya kerusakan barang di gudang}

Pada masa sekarang ini banyak sekali perusahaan yang berdiri di tengah-tengah kota besar di Indonesia. Perusahanan yang berdiri terdiri dari dua jenis bidang usaha, yaitu bidang manufaktur dan bidang jasa. Semua perusahaan baik perusahaan manufaktur maupun perusahaan yang memberikan jasa pasti memiliki satu tujuan yang sama, yaitu memperoleh keuntungan atau laba.

Dalam memperoleh keuntungan atau laba, perusahaan harus memiliki kualitas internal dan eksternal yang baik. Kualitas internal dapat dilihat dari baiknya hubungan antar pekerja dan bagaimana lancarnya proses produksi mulai dari pembelian bahan baku sampai pengiriman dan penjualan barang jadi. Sedangkan kualitas eksternal dapat dilihat dari bagaimana perusahaan memiliki kualitas pelayanan yang baik saat pelanggan memberikan kritik maupun saran melalui telefon maupun laman jika ada(Jessica Juventia, 2016).

\section{PT. Indomarco Prismatama}

Indomaret merupakan jaringan minimarket yang menyediakan kebutuhan pokok dan kebutuhan sehari-hari dengan luas jangkauan kurang dari $200 \mathrm{~m} 2$.Dikelola oleh PT. Indomarco Prismatama, cikal bakal pembukaan Indomaret di Kalimantan dan toko pertama dibuka di Ancol, Jakarta Utara.Toko pertama Indomaret dibuka pada bulan Agustus 1987.

Tahun 1997 perusahaan mengembangkan bisnis gerai waralaba pertama di Indonesia, setelah Indomaret teruji dengan lebih dari 230 gerai.Pada Mei 2003 Indomaret meraih penghargaan "Perusahaan waralaba 2003" dari presiden Megawati Soekarno Putri.Hingga Januari 2010 Indomaret mencapai 3967 gerai. Dari total itu 220, gerai adalah milik sendiri dan sisanya 1764 gerai waralaba milik masyarakat, yang tersebar Jabotabek, Jawa Barat, Jawa Tengah, Jawa Timur, DIY, Bali,Medan, Lampung, Pekanbaru, Batam, Pontianak, Makasar. Di DKI Jakarta terdapat sekitar 688 gerai. 


\section{METODE PENELITIAN}

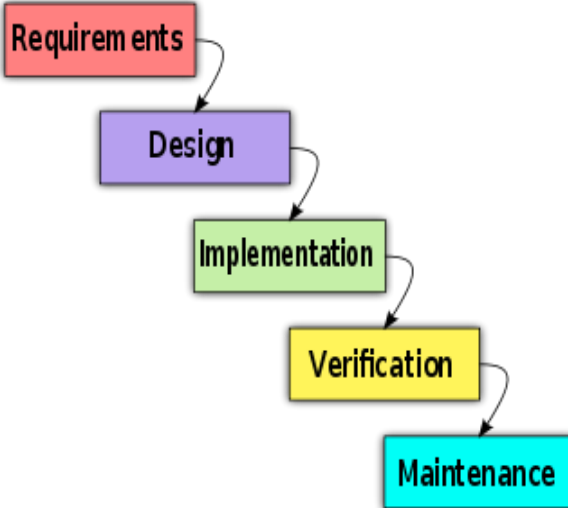

Gambar 2.1 Metode Pengembangan Perangkat lunak

1. Analisa kebutuhan (Requirements)

Tahap pertama yang menjadi dasar proses pembuatan software secara keseluruhan dan kelengkapan fitur software yang dihasilkan sangat tergantung pada hasil analisa kebutuhan ini. Untuk memperoleh informasi tentang proses penjualan dan persediaan yang ada diindomaret, dilakukan wawancara, diskusi dan survey ke lapangan. Dari hasil analisa yang penulis dapatkan, indomaret membutuhkan sebuah program yang dapat mengambil keputusan yang berhubungan dengan inventory atau EOQ sehingga dapat membantu dalam menyediakan informasi optimal inventory untuk menjaga kelancaran arus persediaan produk, serta memungkinkan perusahaan untuk memenuhi permintaan pembelian.

\section{Desain sistem ( Desain)}

Merancang sistem yang menampilkan serta menghasilkan informasi kebutuhan persediaan dengan rincian sebagai berikut ( desain output, desain input, desain file dan database).

3. Penulisan kode program ( implementation) Pembuatan program dengan menggunakan PHP Hypertext Preprocesor (PHP) sebagai aplikasi yang akan digunakan untuk memproses data dan informasi dari hasil analisis dan perancangan. MySqldigunakan sebagai database untuk menyimpan data.

\section{Pengujian program ( verification)}

Menguji sistem yang telah selesai dirancang apakah masih terdapat kesalahan dalam rangcangan logika atau program bila terdapat kesalahan akan dilakukan perbaikanperbaikan sehingga program yang dibuat siap dan layak untuk digunakan.

5. Penerapan program ( maintenance)

Dalam penerapan program ini akan dijelaskan hasil rangcangan dan desain yang telah dilakukan sehingga pada tahapan ini dihasilkan suatu sistem yang dapat berjalan secara optimal. Pada pembuatan aplikasi perbandiangan metode software dan hardware.

\section{HASII DAN PEMBAHASAN}

\subsection{ANALISA SISTEM}

Kegiatan analisa sistem adalah kegiatan untuk melihat sistem yang sudah berjalan, melihat bagaimana yang bagus dan tidak bagus, dan kemudian mendokumentasikan kebutuhan yang akan dipenuhi dalam sistem yang baru. Analisa bertujuan untuk mendapatkan pemahaman secara keseluruhan tentang sistem yang akan dibuat.

\subsubsection{Analisa Metode EOQ}

Analisa Metode Economic Order Quantity ( EOQ) ini adalah tahapan penyelesaiaan masalah dalam bentuk tabel. 
1. Tabel dalam menentukan penjualan dalam satu periode ( D)

Tabel 3.1 Produk Item dalam penjualan

\begin{tabular}{|l|l|l|}
\hline NO & $\begin{array}{l}\text { PRODUCT } \\
\text { CODE }\end{array}$ & DESCRIPTION \\
\hline 1 & 10010220 & SARIWANGI TEH CELUP (19565) BOX ASLI 50X1.9g \\
\hline 2 & 20047761 & TOP COFFEE WHITE COFFEE PCK 9x21g \\
\hline 3 & 10004906 & BEAR BRAND SUSU ENCER STERIL KLG 189mL \\
\hline 4 & 20040299 & SGM EKSPLOR 3 SUSU PERTUMBUHAN PRESINUTRI BOX MADU \\
\hline 5 & 20021178 & MINUTE MAID JUICE BTL PULPY ORANGE 350mL \\
\hline 6 & 20005835 & ADES AIR MINERAL BTL 600mL \\
\hline 7 & 10003814 & AQUA AIR MINERAL PRIMA BTL 600mL \\
\hline 8 & 20005529 & NESTLE AIR MINERAL BTL PURE LIFE 600mL \\
\hline 9 & 20032785 & BIG SOFT DRINK BTL COLA 535mL \\
\hline 10 & 20009737 & YOU C1000 HEALTH DRINK VITAMIN BTL ORANGE 140mL \\
\hline
\end{tabular}

Tabel 3.2. Penjualan, Stock Out dan Hari Jual

\begin{tabular}{|l|l|l|l|l|l|l|l|l|l|l|}
\hline & PRDCD & HARGA & BIA( H ) & AQTY & BQTY & STO1 & STO2 & AHJ & BHJ & JLH TOKO \\
\hline 1 & 10010220 & 9,400 & 940 & 272 & 245 & 10 & 1 & 712 & 647 & 23 \\
\hline 2 & 20047761 & 10,600 & 1,060 & 125 & 94 & 13 & 9 & 712 & 647 & 23 \\
\hline 3 & 10004906 & 7,350 & 735 & 8,478 & 7,960 & 0 & 0 & 712 & 647 & 23 \\
\hline 4 & 20040299 & 35,000 & 3,500 & 261 & 206 & 9 & 44 & 712 & 647 & 23 \\
\hline 5 & 20021178 & 6,650 & 665 & 3,120 & 2,780 & 3 & 2 & 712 & 647 & 23 \\
\hline 6 & 20005835 & 3,200 & 320 & 5,278 & 4,996 & 1 & 3 & 712 & 647 & 23 \\
\hline 7 & 10003814 & 3,000 & 300 & 20,647 & 17,873 & 0 & 10 & 712 & 647 & 23 \\
\hline 8 & 20005529 & 3,000 & 300 & 398 & 1,221 & 476 & 211 & 712 & 647 & 23 \\
\hline 9 & 20032785 & 3,000 & 300 & 1,244 & 1,101 & 24 & 49 & 712 & 647 & 23 \\
\hline 10 & 20009737 & 6,100 & 610 & 2,060 & 2,066 & 92 & 3 & 712 & 647 & 23 \\
\hline
\end{tabular}

Keterangan :

a. AQTY diatas adalah penjualan pada bulan januari dan BQTY adalah penjualan pada februari, begitu juga untuk bulan berikutnya. Sedangkan ST01 adalah stock out pada bulan januari dan ST02 adalah stock out pada bulan februari, begitu juga untuk bulan berikutnya. Dan AHJ adalah hari jual pada bulan januari dan BHJ adalah hari jual pada bulan februari, begitu juga dengan bulan berikutnya.

b. Biaya Gudang untuk masing-masing item senilai $10 \%$ dari harga Item itu sendiri

c. Biaya dalam setiap pemesanan senilai Rp. 50.000, biaya tersebut adalah biaya telpon ke supplier.

Tabel 3.3. Total Kebutuhan setahun

\begin{tabular}{|l|l|l|l|l|l|l|l|l|}
\hline NO & \multicolumn{1}{|c|}{ PRDCD } & $\begin{array}{c}\text { BIA } \\
(\mathbf{H})\end{array}$ & $\begin{array}{c}\text { JLH } \\
\text { TOKO }\end{array}$ & $\begin{array}{c}\text { TTL } \\
\text { JUAL }\end{array}$ & $\begin{array}{c}\text { TTL ST } \\
\text { OUT }\end{array}$ & $\begin{array}{c}\text { TTL } \\
\text { HJ }\end{array}$ & D HARI & D TAHUN \\
\hline 1 & 10010220 & 940 & 23 & 3,187 & 279 & 8,398 & 0.39 & 3,295 \\
\hline 2 & 20047761 & 1,060 & 23 & 1,260 & 117 & 8,398 & 0.15 & 1,277 \\
\hline 3 & 10004906 & 735 & 23 & 100,009 & 201 & 8,398 & 12.20 & 102,425 \\
\hline 4 & 20040299 & 3,500 & 23 & 4,438 & 105 & 8,398 & 0.54 & 4,493 \\
\hline 5 & 20021178 & 665 & 23 & 45,371 & 152 & 8,398 & 5.50 & 46,191 \\
\hline 6 & 20005835 & 320 & 23 & 57,687 & 64 & 8,398 & 6.92 & 58,109 \\
\hline 7 & 10003814 & 300 & 23 & 254,107 & 87 & 8,398 & 30.57 & 256,675 \\
\hline 8 & 20005529 & 300 & 23 & 30,847 & 1,448 & 8,398 & 4.44 & 37,261 \\
\hline 9 & 20032785 & 300 & 23 & 13,961 & 474 & 8,398 & 1.76 & 14,791 \\
\hline 10 & 20009737 & 610 & 23 & 28,958 & 192 & 8,398 & 3.53 & 29,625 \\
\hline
\end{tabular}


Keterangan :
a. JLH TOKO =Jumlah Toko
b. TTL JUAL $=$ Total Jual
c. TTL ST OUT = Total Stock Out
d. TTL HJ = Total Harga Jual
e. D Hari $=$ Sales Per Day
f. $\quad$ Tahun $=$ Sales Per Tahun

Rumus menghitung EOQ

$E O Q=\sqrt{(2 X D X S) / H}$

Rumus Frekuensi Pemesanan (FP) :

$F P=D / E O Q$

Rumus Safety Stock ( SS ):

$S S=\partial x Z$

$\partial=\sqrt{\sum(\text { Kuadran Deviasi })} / \mathrm{N}$

Rumus ReOrder Point ( ROP ):

$R O P=S S+(4 x$ Keb Hari $)$

Keb Hari $=$ D $/$ Hari

Rumus Persediaan Maximal ( PM ) :

$P M=E O Q+S S$

Total Invenventory Cost ( TIC ) :

$T I C=\sqrt{2 \times D \times S \times H}$

Tabel 3.4. Perhitungan EOQ

\begin{tabular}{|l|l|l|l|l|l|l|l|l|l|l|}
\hline NO & PRDCD & D TAHUN & EOQ & FP & @ (DEV) & SS & Keb Hari & ROP & PM & TIC \\
\hline 1 & 10010220 & 3,295 & 592 & 6 & 780 & 1,288 & 9 & 1,324 & 1,880 & 556,563 \\
\hline 2 & 20047761 & 1,277 & 347 & 4 & 269 & 443 & 3 & 457 & 790 & 367,966 \\
\hline 3 & 10004906 & 102,425 & 3,733 & 27 & 28,490 & 47,008 & 281 & 48,131 & 50,741 & $2,743,760$ \\
\hline 4 & 20040299 & 4,493 & 358 & 13 & 1,193 & 1,969 & 12 & 2,018 & 2,328 & $1,253,956$ \\
\hline 5 & 20021178 & 46,191 & 2,636 & 18 & 12,573 & 20,746 & 127 & 21,252 & 23,382 & $1,752,624$ \\
\hline 6 & 20005835 & 58,109 & 4,261 & 14 & 15,545 & 25,648 & 159 & 26,285 & 29,910 & $1,363,633$ \\
\hline 7 & 10003814 & 256,675 & 9,250 & 28 & 71,426 & 117,852 & 703 & 120,665 & 127,102 & $2,774,934$ \\
\hline 8 & 20005529 & 37,261 & 3,524 & 11 & 9,739 & 16,069 & 102 & 16,477 & 19,593 & $1,057,268$ \\
\hline 9 & 20032785 & 14,791 & 2,220 & 7 & 3,629 & 5,987 & 41 & 6,150 & 8,208 & 666,127 \\
\hline 10 & 20009737 & 29,625 & 2,204 & 13 & 7,916 & 13,061 & 81 & 13,386 & 15,265 & $1,344,293$ \\
\hline
\end{tabular}

Keterangan :

a. $E O Q=$ Economic Order Quantity

b. $\mathrm{FP}=$ Frekuensi Pemesanan 
c. $\mathrm{SS}=$ Safety Stock

d. $R O P=$ Reorder Point

e. $\mathrm{PM}=$ Persediaan Maximal

f. $\quad$ TIC $=$ Total Inventory Cost

\subsection{IMPLEMNTASI SISTEM}

Implementasi sistem merupakan tahap penerapan dan sekaligus pengujian terhadap sistem berdasarkan hasil analisa dan perancangan yang telah dilakukan. Implementasi sistem yang dibuat berbasis web tetapi hanya dapat diakses dalam Local Area Network (LAN)

Yang mana file-filesistem yang dibuat diletakkan di server namun tidak bias diakses untuk umum, system cukup dikonfigurasi di server.Berdasarkan implementasi system diatas terdapat interface (antarmuka) login sistem yang diakses oleh user (pengguna) dan penggunas ebagai berikut:

\section{Menu Login}

Gambaran halaman login dapat dilihat pada gambar 3.1 berikut :

\section{Silahkan Login Development}

\begin{tabular}{|c|c|}
\hline User Name & : username \\
\hline \multirow[t]{2}{*}{ Password } & $: \mid * * * * * * * * * * *$ \\
\hline & Login \\
\hline
\end{tabular}

\section{Gambar 3.1 Menu Login}

\section{Menu Utama}

Menu Utama merupakan tampilan awal setelah melakukan login, dapat dilihat padag ambar 3.2 berikut :

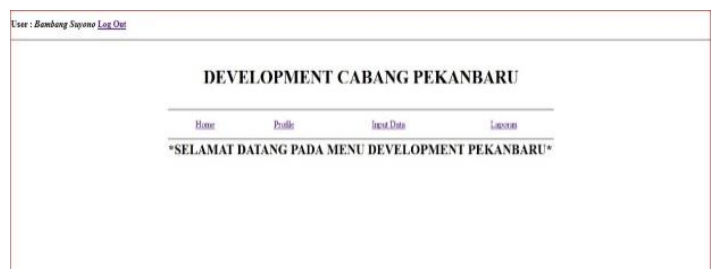

\section{Gambar 3.2. Menu Utama}

\section{Upload Data Toko}

Menu Upload Data took ini merupakan tampilan menu upload data took dalam format csv, dapat dilihat pada gambar 3.3 berikut :

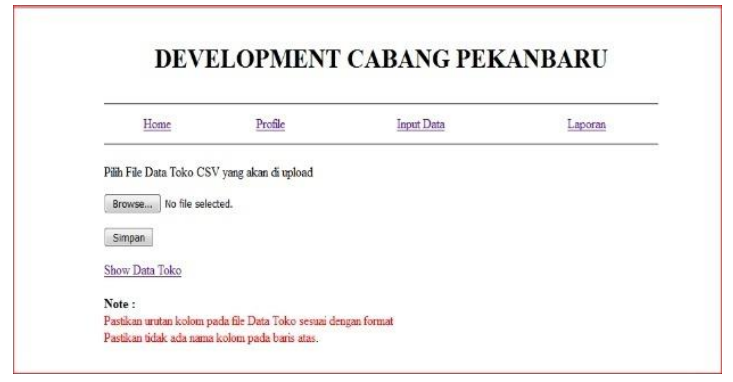

Gambar 3.3. Upload Data Toko

\section{Tampilan Data Toko}

Tampilan Data Toko ini adalah menampilkan semua data toko yang telah tersimpan dalam database toko.

$\underline{\text { Home }} \quad \underline{\text { Profile }} \quad \underline{\text { Input Data }}$ Laporan

\begin{tabular}{|c|c|c|c|c|c|c|c|}
\hline \multicolumn{8}{|c|}{ mbah } \\
\hline No & $\begin{array}{l}\text { Kode } \\
\text { Toko }\end{array}$ & Nama Toko & $\begin{array}{l}\text { Initial } \\
\text { AM }\end{array}$ & $\begin{array}{l}\text { Initial } \\
\text { AS }\end{array}$ & Tgl GO & No Telp & Aksi \\
\hline 1 & TOBW & $\begin{array}{c}\text { KAHARUDIN NASUTION } \\
105\end{array}$ & HRF & BSA & $2014-12-10$ & 2147483647 & Ubah \\
\hline 2 & TONX & $\begin{array}{c}\text { RIAU NO. } 22 \text { (GRAND } \\
\text { E/009 }\end{array}$ & HRF & BSA & $2014-12-10$ & 2147483647 & \\
\hline 3 & T8B4 & PAUS 25 & $\mathrm{HRF}$ & BSA & $2014-12-10$ & 2147483647 & Ubah Hapus \\
\hline 4 & TA0T & SEMBILANG 5-6 & HRF & BSA & $2014-12-10$ & 2147483647 & Ubah Hapus \\
\hline 5 & TB9S & NANGKA 124 & HRF & BSA & 2014-12-10 & 2147483647 & Ubah Hapus \\
\hline 6 & TBK2 & RIAU EX MOKAS/009 & HRF & BSA & 2014-12-10 & 2147483647 & Ubah Hapus \\
\hline 7 & TDDI & SUBRANTAS 56 & HRF & BSA & 2014-12-10 & 2147483647 & Ubah Hapus \\
\hline 8 & TEI6 & PEPAYA/009 & HRF & BSA & $2014-12-10$ & 2147483647 & Ubah Hapus \\
\hline 9 & TFL7 & NANGKA 285 & HRF & BSA & 2014-12-10 & 2147483647 & Ubah Hapus \\
\hline 10 & TGM4 & SUBRANTAS 7-8 & HRF & BSA & 2014-12-10 & 2147483647 & Ubah Hapus \\
\hline 11 & THEL & SUBRANTAS 1-2 A & $\mathrm{HRF}$ & BSA & 2014-12-10 & 2147483647 & Ubah Hapus \\
\hline 12 & TI3N & HANGTUAH $1 \mathrm{AB}$ & HRF & BSA & 2014-12-10 & 2147483647 & Ubah Hapus \\
\hline
\end{tabular}

Gambar. 3.4 Tampilan Data Toko

\section{TampilanTambah Data Toko}

Tampilan tambah Data Toko berikut adalah menu tampilan yang dapat menambahkan data toko satu persatu, apabila diperlukan jika ada opening toko dalam setiap bulannya dana akan tersimpan dalam database toko.

\section{DEVELOPMENT CABANG PEKANBARU}

\begin{tabular}{|c|c|c|c|}
\hline Home & Proffle & Inouit Data & Laporan \\
\hline KODE TOKO & TMT & KECAMATAN & TAMPAN \\
\hline NAMA TOKO & SUARANTAS 123 & KAB/KOTA & PEKANBARU \\
\hline INTTIAL AM & TIO & KODE POS & 28812 \\
\hline DNTILAL AS & PRU & КЕт ТОКО & STD \\
\hline NAMA AM & TRIO ALDRIANTOO & JENIS TOKO & PERUMAHAN \\
\hline NAMA AS & PATAR PASARIBU & CABANG & 20 \\
\hline TGL GO & $2016-11-13$ & DC KIRIM & 6049 \\
\hline TELEPON & 853566066674 & TYPE TOKO & REGUUAR \\
\hline TOTAL KK & 1234 & TYPE HARGA & $F$ \\
\hline ALAMAT & PEKANBAARU KOTA & TYPE RAK & $63+8$ \\
\hline RT & 23 & DOMANN & RESDEEMT \\
\hline $\mathrm{RW}$ & 12 & SUB DOMAIN & TRAFFC \\
\hline KELURAHAN & SIMPPAMG BARU & SOSIO CLASS & MENENGAH \\
\hline
\end{tabular}

Gambar 3.5 TampilanTambah Data Toko 


\section{UploadProdmast}

Upload Prodmast ini berfungsi untuk mengupload Data Produk master barang dalam bentuk csv.

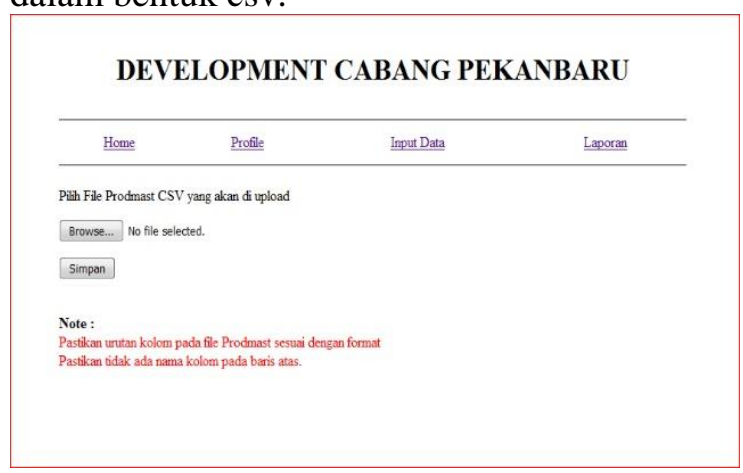

Gambar 3.6 Upload Prodmast

\section{UploadGabungst}

Upload Data Gabung ini berfungsi untuk mengupload data penjualan selama setahun yang sudah dilewati dalam bentuk csv, guna perhitungan Economic Order Quantity di tahun berikutnya.

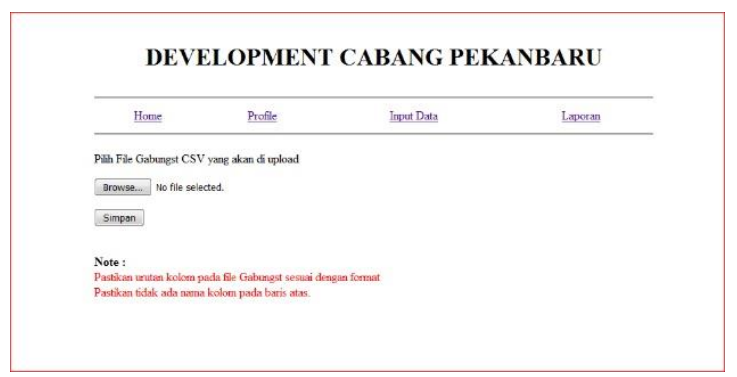

Gambar 3.7 Upload Gabungst

\section{Laporan Economic Order Quantity}

Laporan Economic Order Quantity (EOQ ) dapat dilihat pada gambar 3.8 berikut

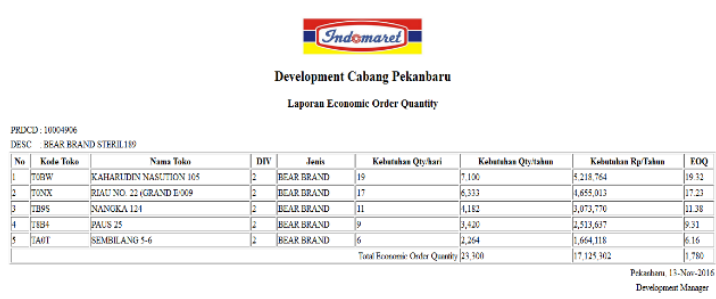

Gambar 3.8 Laporan Economic Order Quantity (EOQ)

\section{Laporan Safety Stock}

Laporan Safety Stock ( SS ) dapat dilihat pada gambar 3.9 berikut :

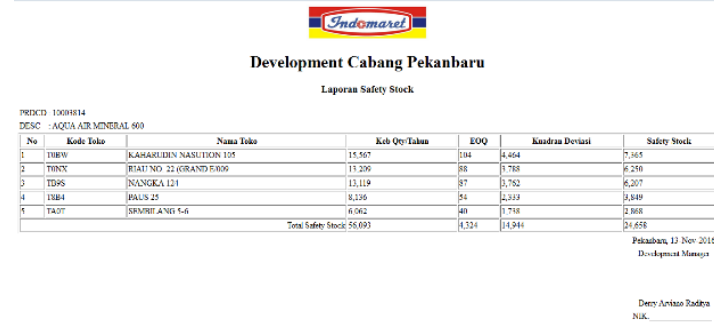

Gambar 3.9 Laporan Safety Stock ( SS )

\section{LaporanReOrder Point}

Laporan ReOrder Point ( ROP ) dapat dilihat pada gambar 3.10 berikut :

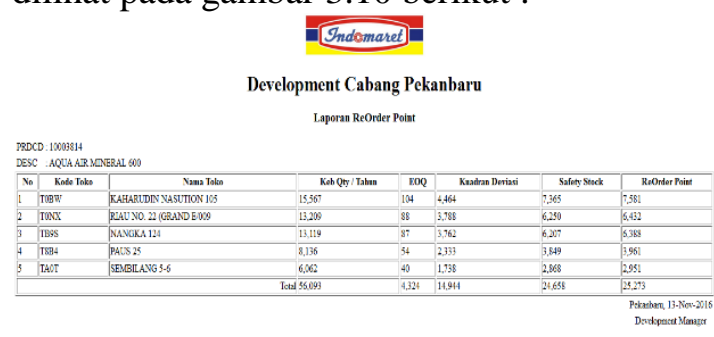

Gambar 3.10 Laporan ReOrder Point ( ROP )

\section{LaporanFrekuensiPesan}

Laporan Frekuensi Pesan( FP ) dapat dilihat pada gambar 3.11 berikut:

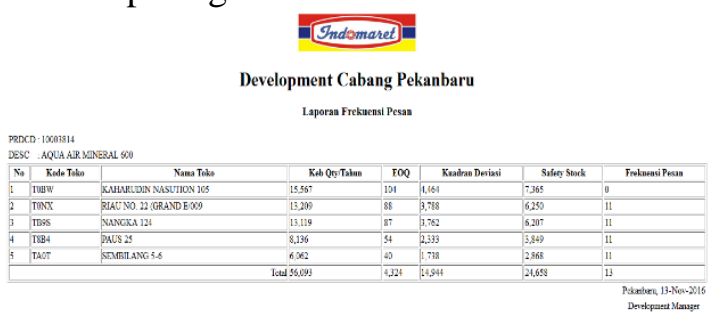

Gambar 3.11 Laporan Frekuensi Pesan( FP )

\section{SIMPULAN}

Setelah melakukan penelitian pada PT. Indomarco Prismatama, maka dapat disimpulkan sebagai berikut:

1. Sistem inventori dengan analisa Economic Order Quantity dapat dilakukan pengendalian stok secara efektif.

2. Sisteminventori dengan analisa Economic Order Quantity dapat mengendalikan persedian dari kelebihan dan kekurangan stok.

3. Sistem inventori dengan analisa Economic Order Quantity, pimpinan PT.Indomarco Prismatama dapat dengan mudah dan 
cepat mendapatkan laporan pemesanan dan pemasok.

\section{UCAPAN TERIMAKASIH}

Ucapan terimakasih kepada STMIK Amik Riau, PT. Indomarco Prismatama dan semua pihak yang telah membantu atas bantuan melakukan penelitian ini.

\section{DAFTAR PUSTAKA}

Amrillah, A. F., Za, Z., \& Np, M. G. W. E. (2016). Analisis Metode Economic Order Quantity (EOQ) Sebagai Dasar Pengendalian Persediaan Bahan Baku Pembantu (Studi Pada PG . Ngadirejo Kediri - PT . Perkebunan Nusantara X). Jurnal EOQ, 33(1), 35-42.

Andira, O. E. (2014). Analisis persediaan bahan baku tepung terigu menggunakan metode eoq. Jurnal Ekonomi Bisnis, 21(3), 201-208.

Gede Agus Darmawan, Wayan Cipta, N. N. Y. (2015). Penerapan economic order quantity ( eoq ) dalam pengelolaan persediaan bahan baku tepung pada usaha pia ariawan di desa banyuning tahun 2013. Jurnal Bisma Universitas Pendidikan Ganesha, 3(1), 110.

Hotasadi. (2017). DALAM PENGENDALIAN PERSEDIAAN BAHAN BAKU PADA LE , TaT BAKERY Hotasadi , S . E Dosen Tetap Prodi Akuntansi Politeknik Sekayu Email: hot454di@gmail.com Julia Nurul Arofah. Jurnal ACSY Politeknik Sekayu, VI(2), 87-98.

Jessica Juventia, L. P. S. H. (2016). Analisis Persediaan Bahan Baku PT . BS dengan Metode Economic Order Quantity ( EOQ ). Gema Aktualita, 5(1), 55-64.

Kustanto, Y. W. K. (2015). Kata Kunci: Duta.com, 2(April), 78-91.

Saragi, G. L., \& Setyorini, R. (2014). Analisis Pengendalian Persediaan Bahan Baku Daging Dan Ayam Dengan Menggunakan Metode Economic Order Quantity ( Eoq ) Pada Restoran Steak Ranjang Bandung. Analisis Pengendalian Persediaan Bahan Baku Daging Dan Ayam Dengan Menggunakan Metode Economic Order Quantity ( Eoq ) Pada Restoran Steak Ranjang Bandung, 1(3), 1-10.

Suryani, E. (2012). Analisis Pengendalian Persediaan Produk Dengan Metode EOQ Menggunakan Algoritma Genetika untuk Mengefisiensikan Biaya Persediaan. Jurnal Teknik ITS, 1, A305-A309.

Syamfithriani, T. S., Muhamad, A., \& Putra, M. D. E. (2016). SUPPLY CHAIN
MANAGEMENT ( Studi Kasus : PT . Aretha Nusantara Farm ). Jurnal Cloud Information, 1, 42-49.

Wardhani, P. S. (2015). Perencanaan dan Pengendalian Persediaan Komponen dengan menggunakan Metode EOQ. Media Mahardika, 13(3), 310-328. 